3-16-2018

\title{
In Vivo EPR Assessment of pH, p02, Redox Status, and Concentrations of Phosphate and Glutathione in the Tumor Microenvironment
}

\author{
Andrey A. Bobko \\ West Virginia University \\ Timothy D. Eubank \\ West Virginia University \\ Benoit Driesschaert \\ West Virginia University \\ Valery V. Khramtsov \\ West Virginia University
}

Follow this and additional works at: https://researchrepository.wvu.edu/ctsi

Part of the Medicine and Health Sciences Commons

\section{Digital Commons Citation}

Bobko, Andrey A.; Eubank, Timothy D.; Driesschaert, Benoit; and Khramtsov, Valery V., "In Vivo EPR Assessment of $\mathrm{pH}, \mathrm{pO2}$, Redox Status, and Concentrations of Phosphate and Glutathione in the Tumor Microenvironment" (2018). Clinical and Translational Science Institute. 813.

https://researchrepository.wvu.edu/ctsi/813

This Article is brought to you for free and open access by the Centers at The Research Repository @ WVU. It has been accepted for inclusion in Clinical and Translational Science Institute by an authorized administrator of The Research Repository @ WVU. For more information, please contact ian.harmon@mail.wvu.edu. 


\title{
Video Article \\ In Vivo EPR Assessment of $\mathrm{pH}, \mathrm{pO}_{2}$, Redox Status, and Concentrations of Phosphate and Glutathione in the Tumor Microenvironment
}

\author{
Andrey A. Bobko ${ }^{1,2}$, Timothy D. Eubank ${ }^{1,3}$, Benoit Driesschaert ${ }^{1,2}$, Valery V. Khramtsov ${ }^{1,2}$ \\ ${ }^{1}$ In Vivo Multifunctional Magnetic Resonance center, Robert C. Byrd Health Sciences Center, West Virginia University \\ ${ }^{2}$ Department of Biochemistry, West Virginia University School of Medicine \\ ${ }^{3}$ Department of Microbiology, Immunology \& Cell Biology, West Virginia University School of Medicine
}

Correspondence to: Valery V. Khramtsov at valery.khramtsov@hsc.wvu.edu

URL: https://www.jove.com/video/56624

DOI: doi:10.3791/56624

Keywords: Cancer Research, Issue 133, Electron paramagnetic resonance, nitroxide, trityl radical, pH, oxygen concentration, redox status, glutathione, inorganic phosphate, tumor microenvironment

Date Published: 3/16/2018

Citation: Bobko, A.A., Eubank, T.D., Driesschaert, B., Khramtsov, V.V. In Vivo EPR Assessment of pH, $p \mathrm{O}_{2}$, Redox Status, and Concentrations of Phosphate and Glutathione in the Tumor Microenvironment. J. Vis. Exp. (133), e56624, doi:10.3791/56624 (2018).

\section{Abstract}

This protocol demonstrates the capability of low-field electron paramagnetic resonance (EPR)-based techniques in combination with functional

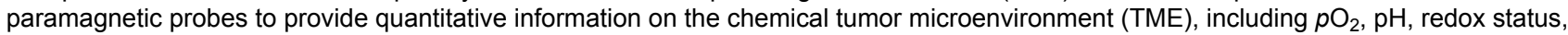
concentrations of interstitial inorganic phosphate (Pi), and intracellular glutathione (GSH). In particular, an application of a recently developed soluble multifunctional trityl probe provides unsurpassed opportunity for in vivo concurrent measurements of $\mathrm{pH}, p \mathbf{O}_{2}$ and $\mathbf{P i}$ in Extracellular space (HOPE probe). The measurements of three parameters using a single probe allow for their correlation analyses independent of probe distribution and time of the measurements.

\section{Video Link}

The video component of this article can be found at https://www.jove.com/video/56624/

\section{Introduction}

\section{A key role of the TME in cancer progression and therapy is increasingly appreciated ${ }^{1}$. Among important physiological parameters of the} TME in solid tumors, tissue hypoxia ${ }^{2}$, acidosis ${ }^{3,4}$, high reducing capacity ${ }^{5}$, elevated concentrations of intracellular $\mathrm{GSH}^{6,7}$, and interstitial $\mathrm{Pi}^{8}$ are well documented. Noninvasive in vivo $\mathrm{pO}_{2}, \mathrm{pH}, \mathrm{Pi}, \mathrm{GSH}$, and redox assessments provide unique insights into the biological processes in TME, and help advance tools for pre-clinical screening of anti-cancer drugs and TME-targeted therapeutic strategies. A reasonable radiofrequency penetration depth in tissues by magnetic resonance imaging (MRI) and low-field EPR-based techniques makes them the most appropriate approaches for noninvasive assessment of these TME parameters. MRI relies largely on imaging water protons and is widely used in clinical settings to provide anatomical resolution but lacks functional resolution. The phosphorus-31 nuclear magnetic resonance $\left({ }^{31} \mathrm{P}\right.$ -

NMR) measurements of extracellular Pi concentration and $\mathrm{pH}$ based on a signal from endogenous phosphate are potentially attractive for TME characterization, but are normally masked by several times higher intracellular Pi concentrations ${ }^{9,10}$. In contrast to this, EPR measurements rely on spectroscopy and imaging of specially designed paramagnetic probes to provide functional resolution. Note that exogenous EPR probes have an advantage over exogenous NMR probes due to the much higher intrinsic sensitivity of EPR and absence of endogenous background EPR signals. The recent development of a dual function $\mathrm{pH}$ and redox nitroxyl probe ${ }^{11}$ and multifunctional trityl probe ${ }^{12}$ provides unsurpassed opportunities for in vivo concurrent measurements of several TME parameters and their correlation analyses independent on probe distribution and time of measurement. To our knowledge, there are no other methods available to concurrently assess in vivo physiologically important chemical TME parameters in living subjects, such as $\mathrm{pO}_{2}, \mathrm{pH}_{\mathrm{e}}, \mathrm{Pi}$, redox, and $\mathrm{GSH}$.

Probes for In Vivo Functional Measurements:

Figure 1 shows chemical structures of the paramagnetic probes used to access TME parameters, which include particulate and soluble probes. High functional sensitivity, stability in living tissue, and minimal toxicity are a few benefits that make particulate probes preferred over soluble probes for in vivo EPR oximetry. For example, particulate probes have increased retention times at the site of tissue implant compared to soluble probes allowing for longitudinal measurement of tissue $\mathrm{pO}_{2}$ over several weeks. On the other hand, soluble probes outperform particulate probes by providing spatial-resolved measurements using EPR-based imaging techniques as well as allowing concomitant analyses from multiple functionalities $\left(\mathrm{pO}_{2}, \mathrm{pH}, \mathrm{Pi}\right.$, redox, and $\left.\mathrm{GSH}\right)$. 


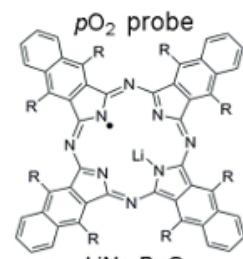

LiNc-BuO

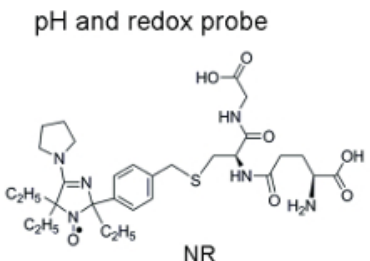

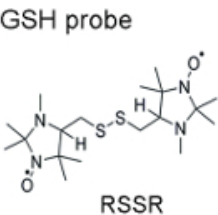

RSSR
$\mathrm{pO}_{2}, \mathrm{pH}$ and $\mathrm{Pi}$ probe

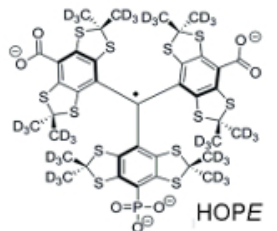

Figure 1. Chemical structures of the paramagnetic probes that assemble TME assessment assay. This includes the particulate $p \mathrm{O}_{2}$ probe, LiNc-BuO $\left(\mathrm{R}=-\mathrm{O}\left(\mathrm{CH}_{2}\right)_{3} \mathrm{CH}_{3}\right)$, and soluble probes: dual function $\mathrm{pH}$ and redox probe, $\mathrm{NR} ; \mathrm{GSH}$-sensitive probe, $\mathrm{RSSR}$; and multifunctional $p \mathrm{O}_{2}$, $\mathrm{pH}$, and $\mathrm{Pi}$ probe of the extracellular microenvironment, the HOPE probe. The synthesis of these probes has been described in the provided references ${ }^{11,12}$. Please click here to view a larger version of this figure.

\section{Protocol}

All animal work was performed in accordance with WVU IACUC approved protocol.

\section{Probe Synthesis and Calibration}

1. Particulate $\mathrm{pO}_{2}$-sensitive LiNc-BuO probe

Note: LiNc-BuO microcrystals are synthesized and prepared as described in reference ${ }^{13}$. They are very stable and can be kept at room temperature for years. The EPR linewidth of the $\mathrm{LiNc}-\mathrm{BuO}$ particulate probe is a $\mathrm{pO}_{2}$-sensitive parameter. LiNc-BuO microcrystals demonstrate ideal linear dependence of the linewidth on oxygen concentration in the range from anoxic conditions up to $760 \mathrm{mmHg}$ of $\mathrm{pO}_{2}$ partial pressure ${ }^{13}$, with the values of intrinsic linewidth in the absence of oxygen and the slope of the oxygen dependence (measured in mG/ $\mathrm{mmHg}$ ) slightly varying for different batches of the microcrystal preparation. Therefore, calibration is required for every particular batch.

1. Weigh $60 \mathrm{mg}$ of LiNc-BuO microcrystals.

2. For oxygen sensitivity calibration, suspend microcrystals in $3 \mathrm{~mL}$ of Dulbecco's Modified Eagle Media (DMEM) medium (in a concentration of $20 \mathrm{mg} / \mathrm{mL}$ ) and sonicate for $5 \mathrm{~min}$ on ice with a probe sonicator at $20 \mathrm{kHz}$ using $7 \mathrm{~W}$ power in a 5 - $\mathrm{mL}$ glass roundbottom tube.

3. Place $1 \mathrm{~mL}$ of the sonicated microcrystals in a glass tube in the surface coil resonator of the L-band (1.2 GHz) EPR spectrometer and acquire continuous waves (CW) EPR spectra at the physiological temperature of $37^{\circ} \mathrm{C}$ and oxygen concentrations of $0,1,2,4,8$, and $20.9 \%$. Maintain the oxygen concentration by bubbling the solution with gas mixture delivered from a gas controller and maintain the temperature using a water bath attached to a thermostat. Use the following EPR spectrometer acquisition parameters: modulation amplitude, $100 \mathrm{mG}$; modulation frequency, $100 \mathrm{kHz}$; sweep width, $5 \mathrm{G}$; sweep time, $60 \mathrm{~s}$.

4. To achieve a better signal-to-noise ratio (SNR), use a modulation amplitude value of $60 \%$ of the linewidth (e.g., use a modulation amplitude $0.6 \mathrm{G}$ for the linewidth of $1 \mathrm{G}$ ).

5. Alternative simplified calibration procedure: Record the EPR spectra in air-bubbled and anoxic solutions ${ }^{14}$. In the latter case, maintain anoxia in the samples by the addition of $10 \mathrm{mM}$ glucose and $100 \mathrm{U} / \mathrm{mL}$ glucose oxidase to $1 \mathrm{~mL}$ probe solutions according to reference ${ }^{14}$

6. Fit the EPR spectra with the Lorentzian function to find the line width, LW. Evaluate the sensitivity of microcrystals to $p \mathrm{O}_{2}$ as a slope of the dependence of $\mathrm{LW}$ on $p \mathrm{O}_{2}$, namely as a value of $\left(\mathrm{LW}_{\text {air }}-\mathrm{LW}_{\text {anoxia }}\right) / p \mathrm{O}_{2 \text { air }}$, where $\mathrm{LW}_{\text {air }}$ and $\mathrm{LW}_{\text {anoxia }}$ are spectra linewidth in air and anoxia conditions, respectively; $\mathrm{pO}_{2 \text { air }}=152 \mathrm{mmHg}$.

2. Dual function $\mathrm{pH}$ and redox probe, $\mathrm{NR}$

Note: The NR probe is synthesized as described in reference ${ }^{11}$. It is stable at room temperature both as a solid and in aqueous solutions. The synthesized NR probe is kept at $4{ }^{\circ} \mathrm{C}$. The nitrogen hyperfine splitting, $a_{N}$, and the signal amplitude decay rate are the spectral parameters of the $\mathrm{NR}$ probe that are sensitive to $\mathrm{pH}$ (probe $\mathrm{pK}_{\mathrm{a}}=6.6$ at $37^{\circ} \mathrm{C}$, range of $\mathrm{pH}$ sensitivity from 5.6 to 7.6 ) and to the reducing capacity of the probe microenvironment, respectively.

1. Remove the NR from the freezer and allow the container to warm to room temperature (10 - $15 \mathrm{~min})$. Weigh out $6.34 \mathrm{mg}$ of the NR, dissolve it in $1 \mathrm{~mL}$ of saline solution, and adjust the $\mathrm{pH}$ to 7.2 with small aliquots of $\mathrm{HCl}$ or $\mathrm{NaOH}$ using a pH meter. Use the prepared NR solution (10 $\mathrm{mM})$ as a stock solution.

2. Perform the $\mathrm{pH}$ calibration of the NR probe as follows (see reference ${ }^{11}$ ). First, add $0.1 \mathrm{~mL}$ of the NR stock solution to $0.9 \mathrm{~mL}$ of $2 \mathrm{mM}$ Na-phosphate buffer, $150 \mathrm{mM} \mathrm{NaCl}$. Titrate the obtained $1 \mathrm{mM} \mathrm{NR}$ solution with aliquots of $\mathrm{HCl}$ or $\mathrm{NaOH}$ to the required $\mathrm{pH}$ using a pH meter. Control the temperature using a water bath attached to a thermostat.

3. Record the EPR spectra of the samples in 1.5-mL microcentrifuge tubes using the L-band EPR spectrometer. Use the following EPR spectrometer acquisition parameters: modulation amplitude, $2.5 \mathrm{G}$; modulation frequency, $100 \mathrm{kHz}$; sweep width, $60 \mathrm{G}$; sweep time, 20 s.

4. Measure the hyperfine splitting constant $\left(\mathrm{a}_{\mathrm{N}}\right)$ as half of the distance between low- and high-field components of the EPR spectra and plot it versus $\mathrm{pH}$, to provide the calibration curve for L-band EPR measurements of $\mathrm{pH}$.

3. GSH-sensitive RSSR probe

Note: The RSSR probe is synthesized as described in reference ${ }^{15}$. Store the synthesized NR probe at $4{ }^{\circ} \mathrm{C}$. The lipophilic RSSR disulfide biradical compound easily diffuses across the cell membrane to react with intracellular GSH and provide a reliable approach for determining GSH in vivo using EPR ${ }^{16,17}$. This method is based on the high reaction rates of the predominant intracellular pool of GSH thiols with the RSSR probe. The reaction of the RSSR biradical with GSH splits its disulfide bond (see Scheme 1) resulting in the cancellation of spin exchange between the two radical fragments and manifesting in a decrease of the biradical spectral components and corresponding increase of the monoradical components. For the biradical RSSR probe, the rate of the increase of the amplitude of the monoradical component is proportional to the GSH concentration and is a convenient GSH-sensitive EPR spectral parameter. To evaluate GSH concentration from the 
in vivo EPR measurements, the preceding calibration of the rate of the RSSR reaction with GSH at the corresponding temperature and $\mathrm{pH}$ has to be performed as follows.

1. Remove the RSSR from the freezer and allow the container to warm to room temperature (10-15 min). Weigh out $4.05 \mathrm{mg}$ of the NR and dissolve it in $1 \mathrm{~mL}$ of DMSO solution. Use the prepared RSSR solution (10 mM) as a stock solution.

2. Determine the value of the rate constant, $\mathrm{k}_{\mathrm{obs}}$, of the reaction of RSSR with $\mathrm{GSH}$ at the desirable temperature and $\mathrm{pH}$ as follows.

3. First, add $20 \mu \mathrm{L}$ of the RSSR stock solution $(10 \mathrm{mM})$ to $0.98 \mathrm{~mL}$ of $1 \mathrm{mM} \mathrm{Na}$-phosphate buffer, $\mathrm{pH} 7.2,150 \mathrm{mM} \mathrm{NaCl}$, to obtain a 0.2 mM RSSR probe solution.

4. Prepare solutions of 1,2 , and $5 \mathrm{mM}$ concentrations of GSH in $0.1 \mathrm{M} \mathrm{Na}$-phosphate buffer at $\mathrm{pH}$ 7.2. To accurately evaluate GSH concentration in the cells of the targeted organ from the in vivo measurements, the in vitro calibration has to be performed at a $\mathrm{pH}$ close to the value of the intracellular $\mathrm{pH}$.

5. Mix equal volumes of $0.2 \mathrm{mM}$ RSSR solution and one of the GSH solutions prepared in step 1.3.4. for a final concentration of the probe at $0.1 \mathrm{mM}$ and of GSH at $0.5,1$, or $2.5 \mathrm{mM}$.

6. Immediately after RSSR and GSH solution mixing, place the sample in the EPR resonator and record the EPR spectra every 12 seconds for 10 minutes. Then calculate the kinetics of the increase of the monoradical spectral amplitude. Use the following EPR spectrometer acquisition parameters: modulation amplitude, $1 \mathrm{G}$; modulation frequency, $100 \mathrm{kHz}$; sweep width, $60 \mathrm{G}$; sweep time, $10-60 \mathrm{~s}$.

7. Fit the measured EPR kinetics to the monoexponents and calculate the time constant of the exponential kinetics, $\mathrm{T}$. The linear regression $\left(1 / \mathrm{T}=\mathrm{k}_{\mathrm{obs}} \times[\mathrm{GSH}]\right)$ provides the observed rate constant value of the reaction between $\mathrm{GSH}$ and $\mathrm{RSSR}\left(e . g .\right.$, at $34^{\circ} \mathrm{C}$ and $\left.\mathrm{pH} 7.2, \mathrm{k}_{\mathrm{obs}}=2.8 \pm 0.2 \mathrm{M}^{-1} \mathrm{~s}^{-1}\right)^{11}$.

4. Multifunctional $\mathrm{HOPE}$ probe for $\mathrm{pO}_{2}, \mathrm{pH}$, and $\mathrm{Pi}$ assessment

Note: The monophosphonated trityl HOPE probe is synthesized as described in reference ${ }^{12}$ and is kept at $4{ }^{\circ} \mathrm{C}$. The CW EPR spectra of $\mathrm{HOPE}$ at $\mathrm{pH} \ll<\mathrm{pK}_{\mathrm{a}}(\mathrm{A}-$ acid form $)$ and $\mathrm{pH} \gg>\mathrm{pK}_{\mathrm{a}}(\mathrm{B}$ - basic form) are represented by the doublets due to phosphorus hyperfine splitting, ap. The typical instrument settings are as follows: modulation amplitude, $37.5 \mathrm{mG}$; modulation frequency, $100 \mathrm{kHz}$; sweep width, $0.9 \mathrm{G}$; sweep time, $20-60 \mathrm{~s}$. At intermediate $\mathrm{pH}(5<\mathrm{pH}<8)$ the EPR spectrum of HOPE probe is characterized by a quartet when both $\mathrm{A}$ and $\mathrm{B}$ states are present. The individual EPR linewidth of the HOPE is a $p \mathrm{O}_{2}$ marker (accuracy, $\approx 1 \mathrm{mmHg} ; \mathrm{O}_{2}$ range, $1-100 \mathrm{mmHg}$ ). The fraction of protonated HOPE (A form) is a pH marker in the range from 6 to 8.0 (accuracy, \pm 0.05 ). The value of the proton exchange rate (expressed in $\mathrm{mG}$ ) with Pi extracted by spectra simulation is a Pi marker (accuracy, $\pm 0.1 \mathrm{mM}$, range, $0.1-20 \mathrm{mM}$ ). Calibration procedures are performed at physiological temperature $\left(37^{\circ} \mathrm{C}\right)$, solution ionic strength $(\mathrm{NaCl}, 150 \mathrm{mM})$, and $\mathrm{HOPE}$ probe concentration of $0.2 \mathrm{mM}$, as previously described in references ${ }^{12,18}$, and detailed below.

1. Remove the HOPE probe from the freezer and allow the container to warm to room temperature (10-15 min).

2. Weigh out $10.7 \mathrm{mg}$ of the HOPE probe, dissolve it in $1 \mathrm{~mL}$ of saline solution, and adjust the $\mathrm{pH}$ to 7.4 . Add $20 \mu \mathrm{L}$ of the prepared stock solution of the HOPE $(10 \mathrm{mM})$ to $0.98 \mathrm{~mL}$ of the saline solution to obtain a $0.2 \mathrm{mM}$ HOPE probe solution.

3. For probe calibration of the $\mathrm{pH}$, titrate $0.2 \mathrm{mM}$ of the HOPE probe solution by the addition of a small volume of $\mathrm{NaOH}$ or $\mathrm{HCl}$, with the final dilution of sample less than $1 \%$. Measure the $\mathrm{pH}$ with a pH electrode calibrated at $37^{\circ} \mathrm{C}$ using the $\mathrm{pH}$ values for the reference solution recommended by National Bureau of Standards (U.S.). Use a jacketed reaction beaker attached to a circulator to carefully maintain temperature of the reference and titrated solutions during $\mathrm{pH}$ measurements. Maintain anoxic conditions by the addition of 10 $\mathrm{mM}$ glucose and $100 \mathrm{U} / \mathrm{mL}$ glucose oxidase to the probe solutions.

4. Acquire the EPR spectra of the $\mathrm{A}$ and $\mathrm{B}$ forms at $\mathrm{pH} \leq 5$ and $\mathrm{pH} \geq 8$, respectively, in anoxic conditions in the absence of phosphate.

5. Use the corresponding spectra to obtain intrinsic spectral parameters. Namely, simulate the spectral line as the convolution of the Lorentzian function with the Gaussian function that approximates the unresolved super hyperfine structure of the HOPE probe. The fitting of the calculated EPR spectra to the experimental spectra yields the values of $a_{p}$ and Lorentzian linewidth $\left(\Delta \mathrm{L}_{\mathrm{pp}}\right)$, determined by the transverse relaxation rate, $1 / T_{2}$ (where $1 / T_{2}=(\sqrt{3} / 2) L_{p p}$ for the measured derivative of the RF absorption line in CW EPR), and the linewidth of Gaussian distribution, $\mathrm{G}$.

Note: The following are the parameters obtained from the spectra measured at the conditions specified in step 1.4.2: $a_{P}(A)=3.63 \mathrm{G}$, $a_{P}(B)=3.37 \mathrm{G} ; 1 / \mathrm{T}_{2}(A)=23.6 \mathrm{mG} ; 1 / \mathrm{T}_{2}(B)=9 \mathrm{mG} ; \mathrm{G}(\mathrm{A})=40 \mathrm{mG} ; \mathrm{G}(\mathrm{B})=45 \mathrm{mG}$ (see reference $\left.{ }^{8}\right)$.

6. Acquire the EPR spectra of the HOPE at intermediate $\mathrm{pH}(5<\mathrm{pH}<8)$. Simulate the high-filed component of the acquired EPR spectra using the theory of exchange between several sites in non-coupled or loosely coupled systems adapted from reference ${ }^{19}$ as previously described $^{18}$. Use the intrinsic parameters obtained for $A$ and $B$ states (see step 1.4.5) to decrease the number of variables. Fit the calculated spectra to the experimental ones to find the values of the fraction $A\left(p_{A}\right)$, and plot the dependence of the $p_{A}$ value on $p H$. Use the dependence of $\mathrm{p}_{\mathrm{A}}$ on $\mathrm{pH}$ in further studies as a $\mathrm{pH}$ calibration curve.

Note: Fitting the $\mathrm{pH}$ dependence of $\mathrm{p}_{\mathrm{A}}$ with a standard titration curve provides the value of the dissociation constant, $\mathrm{pK} \mathrm{K}_{\mathrm{a}}$ (HOPE) $=6.9^{8}$. In in vivo studies, acquiring the full EPR spectra of the HOPE probe is impractical because of the additional time needed to acquire the gap between low- and high-field components of the phosphorus hyperfine splitting in the EPR spectrum. Therefore, in further exemplified studies only the high-filed component of the EPR spectrum has been measured and analyzed.

7. For probe calibration of $p \mathrm{O}_{2}$, acquire EPR spectra of the HOPE probe at various oxygen concentrations.

8. Control the $\mathrm{pO}_{2}$ values of the solutions by bubbling with gas mixture delivered from a gas controller. Control the solution temperature $\left(37^{\circ} \mathrm{C}\right)$ using a water bath attached to a thermostat.

9. Simulate the EPR spectra and fit them to the experimental ones as described in step 1.4.6 to determine the values of oxygen-induced relaxation rates.

Note: The values of oxygen-induced relaxation rates were $0.49 \mathrm{mG} / \mathrm{mmHg}$ both for $\mathrm{A}$ and $\mathrm{B}$ forms of the HOPE probe as measured at $37^{\circ} \mathrm{C}^{8}$.

10. For probe calibration of [Pi], acquire EPR spectra of the HOPE probe at various phosphate concentrations. Use the HOPE radical solution with a $\mathrm{pH}$ value near $\mathrm{pK}_{\mathrm{a}}\left(\mathrm{pK}_{\mathrm{a}}=6.9 \text { at } 37^{\circ} \mathrm{C}\right)^{18}$ and titrate it with various phosphate concentrations. Maintain the temperature and gas composition as described in above steps.

11. Simulate the EPR spectra and fit them to the experimental ones as described in step 1.4.6 to determine the values of Pi-induced exchange rate.

Note: The dependence of the Pi-induced exchange rate on $[\mathrm{Pi}]$ is used as calibration in further studies. 


\section{Mouse Models of Breast Cancer}

1. MMTV-PyMT spontaneous tumor model

1. Use 4-8 week-old female Friend virus B-type susceptibility/NIH (FVB/N) mouse mammary tumor virus promoter (MMTV) polyoma middle-T antigen (PyMT+) mice with spontaneously formed mammary tumors for in vivo EPR studies.

2. For comparison of tissue microenvironments of normal mammary glands and tumors, use age-matched littermate females deficient in the PyMT oncogene (PyMT-, "wild type") ${ }^{20}$.

3. Subject the mice to L-band EPR spectroscopy once per week for four weeks during isoflurane anesthesia (see probe delivery below).

4. Anesthetize the mouse using an air-isoflurane mixture ( $3 \%$ isoflurane), and place the mouse on an adjustable table in a right, lateral position with the tumor (mammary glands) close to the surface coil resonator.

5. After mouse placement, administer the probe by intratissual (i.t.) injection, tune the EPR spectrometer, and acquire the EPR spectra for 5-10 min.

6. Measure 2-3 mammary tumors (from MMTV-PyMT+ mice) or non-tumor bearing mammary glands (from PyMT- mice) during the same EPR session.

2. Orthotopic MET-1 tumor model

1. Grow FVB/N background Met-1 murine breast cancer cells at $37{ }^{\circ} \mathrm{C}, 5 \% \mathrm{CO}_{2}$, and $95 \%$ relative humidity in DMEM containing $10 \%$ fetal bovine serum (FBS), $10 \mu \mathrm{g} / \mathrm{mL}$ insulin, $5 \mathrm{ng} / \mathrm{mL}$ rhEGF, and 1\% PSA (penicillin G sodium, streptomycin sulfate, and amphotericin B) to $\sim 80 \%$ confluence in a T175 flask.

2. Aspirate the media and rinse the adherent cells with $10 \mathrm{~mL} \mathrm{PBS}\left(1.54 \mathrm{mM} \mathrm{KH}_{2} \mathrm{PO}_{4}, 155 \mathrm{mM} \mathrm{NaCl}\right.$, and $2.71 \mathrm{mM} \mathrm{Na}_{2} \mathrm{HPO}_{4}-7 \mathrm{H}_{2} \mathrm{O}$ without calcium chloride or magnesium chloride, $\mathrm{pH}=7.4$ ).

3. Detach the cells by adding $5 \mathrm{~mL}$ of $0.25 \%$ Trypsin-EDTA solution and rocking the flask. When the cells are detached, add $10 \mathrm{~mL}$ DMEM containing $10 \%$ FBS to the flask and collect the cells.

4. Centrifuge the cell suspension at $132 \times \mathrm{g}$ for $10 \mathrm{~min}$ at $4{ }^{\circ} \mathrm{C}$. Count the cells using a hemocytometer and resuspend to $1 \times 10^{6}$ cells per $100 \mu \mathrm{L}$ minimal DMEM

5. Using an insulin syringe (29G1/2 needle), slowly inject $100 \mu \mathrm{L}$ of tumor cell suspension into the number 4 mammary fat pads of 8 week-old female FVB/N wild type mice.

6. Monitor tumor initiation by palpation (appear after approximately 2-3 weeks), growth (visual), and mouse heath (visual) every other day.

7. Measure tumor dimensions once per week using calipers and determine tumor volumes using the equation:

Volume $=\left(\right.$ width $\left.{ }^{2}\right) \times\left(\frac{\text { length }}{2}\right)$

\section{Probe Delivery for In Vivo Functional Measurements}

1. Use particulate $\mathrm{LiNc}-\mathrm{BuO}$ probe (Protocol I) for $\mathrm{pO}_{2}$ measurements in orthotopic tumor models by implanting tumor cells with internalized LiNc-BuO microcrystals as previously described ${ }^{14,21}$ and detailed below.

1. In the case of the MET-1 tumor model, for internalization of LiNc-BuO microcrystals into MET-1 cells, suspend the LiNc-BuO microcrystals in DMEM at a concentration of $20 \mathrm{mg} / \mathrm{mL}$ and sonicate with a probe sonicator at $20 \mathrm{kHz}$ using $7 \mathrm{~W}$ power in a $5-\mathrm{mL}$ glass round-bottom tube for $5 \mathrm{~min}$ on ice.

2. Add $100 \mu \mathrm{L}(2 \mathrm{mg}$ of LiNc-BuO) of the suspension to a T75 flask with $10 \mathrm{~mL}$ culture media containing MET-1 cells (approximately $30 \%$ confluent). All procedures take place in a biosafety cabinet and the media contains penicillin and streptomycin to minimize potential infection.

3. Incubate the cells at $37^{\circ} \mathrm{C}$ for $72 \mathrm{~h}$ or until they reach $\sim 80 \%$ confluency.

4. Aspirate the media. Wash the cells five times with $10 \mathrm{~mL}$ PBS. Detach the cells with $5 \mathrm{~mL}$ trypsin-EDTA. Collect the cells. Centrifuge as described above in step 2.2.4. Stain a sample of cells with exclusion dye to determine cell viability and quantity.

5. Suspend the cells at a concentration of $1 \times 10^{6}$ per $100 \mu \mathrm{L}$ minimal DMEM.

6. Using an insulin syringe, slowly inject $100 \mu \mathrm{L}$ of cell suspension containing the internalized LiNc-BuO microcrystals into the number 4 mammary fat pads of 8-week-old female FVB/N wild type mice as described in step 2.2.5.

7. Monitor tumor initiation and growth as described in steps 2.2.6 and 2.2.7.

2. Use particulate LiNc-BuO probe (Protocol II) in either spontaneous or orthotopic models. Inject LiNc-OBu microcrystals at the site of interest, e.g., into normal mammary glands or mammary tumors, using an insulin syringe.

3. Soluble probes

1. Anesthetize the mice by inhalation of an air-isoflurane mixture $(1.0 \mathrm{~L} /$ min delivery and $2-3 \%$ of isoflurane $)$ using an anesthesia machine and place them into the gap of the EPR spectrometer.

2. Tune the instrument, then inject the NR $(10-30 \mu \mathrm{L}, 10 \mathrm{mM})$, HOPE probe $(10-30 \mu \mathrm{L}, 0.5-2 \mathrm{mM})$ in saline, pH 7.2, or RSSR probe in DMSO $(10 \mu \mathrm{L}, 10 \mathrm{mM})$ solutions (i.t.)

\section{In Vivo Functional Measurements}

1. For EPR spectroscopic measurements, anesthetize the mice by inhalation of air-isoflurane mixture using an anesthesia machine as described in step 3.3.1.

2. Perform functional measurements using L-band $(1.2 \mathrm{GHz})$ EPR spectrometer as follows

1. Place the surface coil resonator onto a normal mammary gland or a mammary tumor and tune the spectrometer.

2. Acquire the EPR spectra from the implanted particulate probe for 5-10 min over several weeks after implantation. In the case of soluble probes, acquire the EPR spectra immediately after probe injection for 5-10 min. 
3. Analyze the EPR spectra of the NR probe to find the hyperfine splitting, $a_{N}$, and signal amplitude, I(t). Convert the value of $a_{N}$ to the $p H$ value using the calibration curve obtained in step 1.2.4. Analyze the rate of decay of the signal amplitude I(t) as relative change from the initial amplitude, $\mathrm{I}(\mathrm{t}=0)$, calculated in arbitrary units per second $\left(\mathrm{s}^{-1}\right)$.

4. Fit the increase of the monoradical component of the EPR spectrum of GSH-sensitive RSSR probe to the monoexponents to obtain the time constant of the exponential kinetics to calculate GSH concentration.

5. Fit the EPR spectra of high-field component of the multifunctional HOPE probe to the experimental ones as described in (step 1.4.5) to yield the values of $\mathrm{pH}, \mathrm{pO}_{2}$ and $\mathrm{Pi}$.

\section{Statistical Analysis}

1. Perform data processing and statistical analyses. Use a Pearson's $r$ Correlation test (for normally distributed datasets) and Spearman's Rank Order Correlation (for datasets with rejected normality of data distribution) for correlation analyses.

\section{Representative Results}

\section{Tissue $\mathrm{pO}_{2}$ Assessment Using the LiNc-BuO Probes:}

Using the procedure described under step 1.1, we performed the calibration of freshly prepared LiNc-BuO microcrystals suspension. Figure 2 shows the typical oxygen dependence of the linewidth of the LiNc-BuO probe, as well as its exemplified EPR spectra measured in buffer suspension and in breast tumor tissue in female C57BI/6 mice grown after tumor initiation by injection of cells with internalized particles (step 3.1). Using the linewidth calibration allows for the calculation of the tissue $\mathrm{pO}_{2}$ value (equal to $7.5 \mathrm{mmHg}$ for the spectrum (b) shown in the Figure 2)

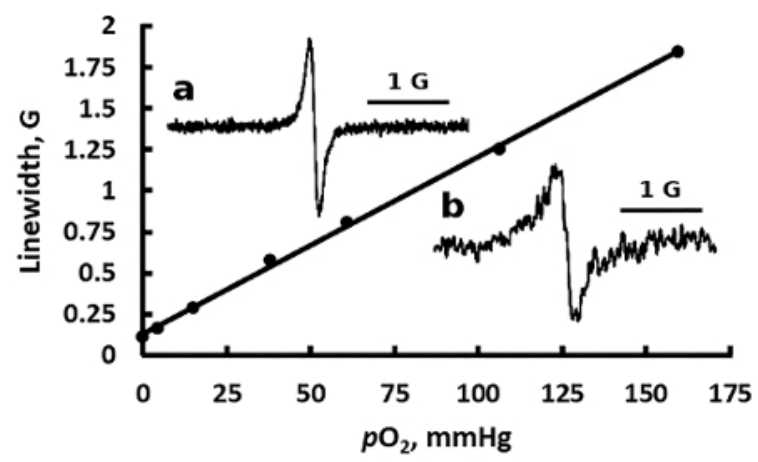

Figure 2. EPR spectral sensitivity of the particulate LiNc-BuO probe to oxygen. Representative dependence of the linewidth of the EPR spectrum of the LiNc-BuO probe suspension in DMEM on oxygen partial pressure is shown. The EPR spectrum (insert a) was measured at $0 \%$ of $p \mathrm{O}_{2}, 37^{\circ} \mathrm{C}$, and represents a pure Lorentzian line with the linewidth $\Delta H_{p p}=113 \mathrm{mG}$. The linewidth increases linearly with $p \mathrm{O}_{2}$ with a slope of $11.7 \mathrm{mG} / \mathrm{mmHg}$. The spectrum shown in (insert b) was measured in mammary tumor tissue of anesthetized female C57BI/6 mice showing $\Delta H_{p p}$ $=204 \mathrm{mG}$, which corresponds to tissue $\mathrm{pO}_{2}$ of $7.5 \mathrm{mmHg}$. Please click here to view a larger version of this figure.

\section{Assessment of Tissue Extracellular pH and Redox Using the NR Probes:}

Using the procedure described under step 1.2, we performed the calibration of the $\mathrm{pH}$ and redox probe, NR. Figure 3 shows the observed hyperfine splitting constant dependence, $\mathrm{a}_{\mathrm{N}}$, of the $\mathrm{NR}$ radical on $\mathrm{pH}$. The dependence is described by a standard titration curve with the $\mathrm{pK}$ 6.6 at $37^{\circ} \mathrm{C}$. This dependence of $\mathrm{a}_{\mathrm{N}}(\mathrm{pH})$ serves as the calibration curve for corresponding in vivo measurements, allowing for $\mathrm{pH}$ measurements in the range from 5.6 to 7.6 , with accuracy of $0.05 \mathrm{pH}$ units. 


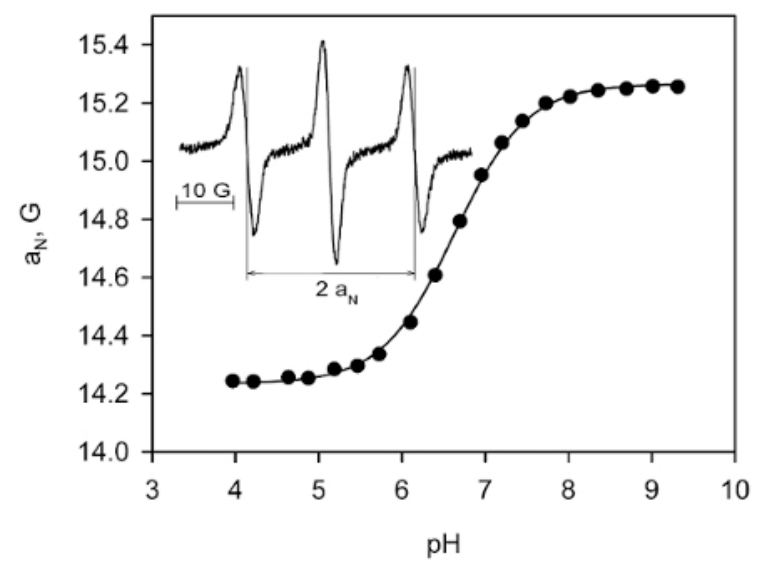

Figure 3. EPR spectral sensitivity of the soluble NR probe to $\mathrm{pH}$. L-band EPR spectra of the NR probe solution were acquired at $37^{\circ} \mathrm{C}$ at various $\mathrm{pH}$, and $\mathrm{pH}$-dependence of the observed hyperfine splitting constant, $\mathrm{a}_{\mathrm{N}}$, was plotted. The solid line is the fit of experimental data with the standard titration curve, $a_{N}=\frac{a_{N}\left(N R-H^{+}\right)+a_{N}(N R) 10^{p H-p K}}{1+10^{p H-p K}}$, yielding pK $\mathrm{a}_{\mathrm{a}}=6.6, \mathrm{a}_{\mathrm{N}}\left(\mathrm{NR}-\mathrm{H}^{+}\right)=14.24 \mathrm{G}$, and $\mathrm{a}_{\mathrm{N}}(\mathrm{R})=15.27 \mathrm{G}$. Insert: Exemplified EPR spectrum of $1 \mathrm{mM} \mathrm{NR}$ solution ( $\mathrm{pH}$ 6.4) acquired using the following spectrometer settings: magnetic field sweep, $80 \mathrm{G}$; modulation amplitude, $2.5 \mathrm{G}$, acquisition time, $20 \mathrm{~s}$. The measured hyperfine splitting constant is $14.63 \mathrm{G}$. Reproduced from reference ${ }^{23}$ with permission of John Wiley \& Sons, Inc. Please click here to view a larger version of this figure.

Figure 4 exemplifies the $\mathrm{pH}$ and redox measurements in a breast tumor mouse model, performed as described under step 3.3 (i.t. probe injection) and section 4 (spectra acquisition and spectra analysis).

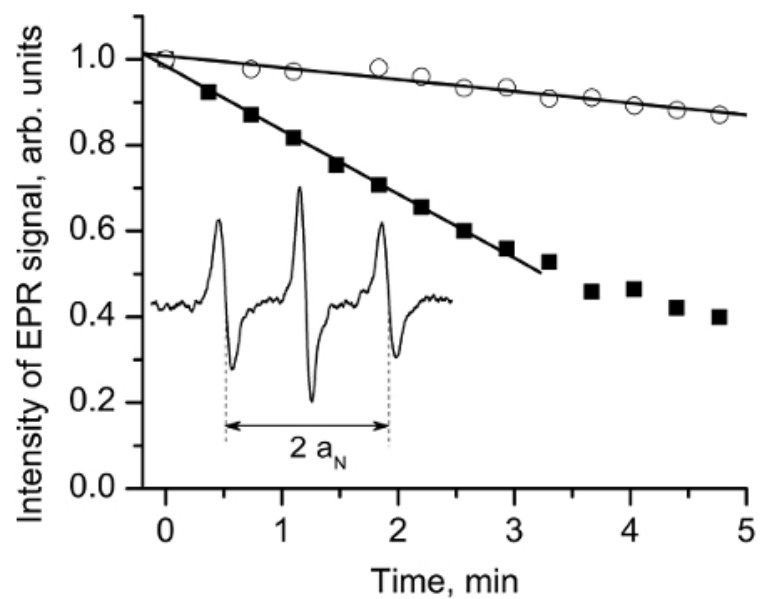

Figure 4. EPR assessment of tissue reducing capacity in vivo. Insert: L-band EPR spectrum of the NR probe measured in vivo after i.t. injection $(10 \mu \mathrm{L}, 10 \mathrm{mM})$ in mammary tumor tissue of anesthetized female $\mathrm{FVB} / \mathrm{N}$ mice. The hyperfine splitting, $a_{\mathrm{N}}$, was found to be equal to $14.72 \mathrm{G}$, which corresponds to the value of $\mathrm{pH}_{\mathrm{e}}=6.52$ assuming tumor tissue temperature $34{ }^{\circ} \mathrm{C}$ and $\mathrm{pK}=6.6$. The $\mathrm{NR}_{\mathrm{a}}$ reduction rate is assessed by following the decay of the central-field spectral component. The exemplified kinetics measured in mammary tumor ( $\mathbf{m})$ and mammary glands (o) demonstrate higher reducing capacity of the tumor tissue vs. normal mammary gland. The analysis of the initial part of the kinetics yields the rates of the EPR signal reduction, $\mathrm{k}_{\text {red, }}$, in the extracellular media of the tissues as $2.5 \times 10^{-3} / \mathrm{s}$ in tumor vs. $0.5 \times 10^{-3} / \mathrm{s}$ in normal gland. Reproduced from reference ${ }^{11}$ with permission of John Wiley \& Sons, Inc. Please click here to view a larger version of this figure.

Figure 5 summarizes the $\mathrm{pH}_{\mathrm{e}}$ and redox measurements performed for the group of female FVB/N MMTV-PyMT mice in tumors and normal mammary glands supporting tumor acidic extracellular microenvironment and high reducing capacity. 


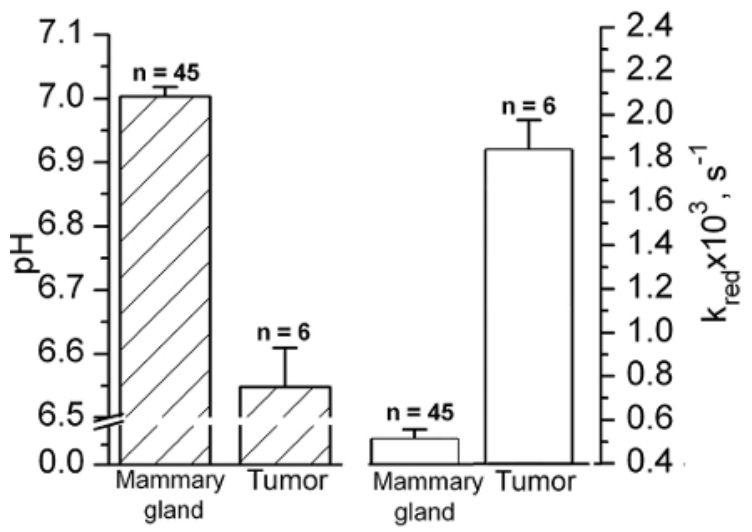

Figure 5. In vivo EPR assessment of tissue acidity and reducing capacity. Extracellular tissue pH (filled bars) and the reduction rate (empty bars) values of NR nitroxide in normal mammary glands and mammary tumors of female FVB/N mice measured by in vivo EPR. Error bars denote SE. Reproduced from reference ${ }^{11}$ with permission of John Wiley \& Sons, Inc. Please click here to view a larger version of this figure.

\section{Concurrent Tissue $\mathrm{pH}_{\mathrm{e}}$, Redox, and $\mathrm{pO}_{2}$ Assessment by Combining NR and LiNc-BuO Probes:}

Particulate LiNc-BuO is the probe of choice when repetitive longitudinal measurements of $\mathrm{pO}_{2}$ values are planned in a predetermined tissue of interest. Unfortunately, a major limitation of the particulate probe is that it only allows for the detection of oxygen and no other physiologicallyrelevant chemical parameters within the TME, and does not allow for tissue imaging. Thus, the use of soluble probes in EPR have the advantage of imaging and the detection of multiple physiologically-relevant TME parameters. In this respect, $\mathrm{pO}_{2}$ measurements using implanted LiNc$\mathrm{BuO}$ particles can be combined with the dual function $\mathrm{pH}$ and redox NR probe because low- and high-field spectral components of the NR EPR spectrum do not overlap with the EPR line of the LiNc-BuO probe.

Figure 6 illustrates a typical EPR spectrum observed by the NR probe immediately after i.t. injection in breast tumor tissue of female C57BI/6 mice. The observed triplet spectrum of the NR probe is overlaid with the single EPR line of LiNc-BuO microcrystals that have been embedded within the tumor (tumor growth was initiated by the injection of the cells with internalized particles as described in step 3.1. The $\mathrm{pH}$ value is calculated by measuring $\mathrm{a}_{\mathrm{N}}$ hyperfine splitting as a distance between low- and high-field components and using the calibration shown in Figure 3 (equal to 6.88) for the spectrum shown in Figure 6. Note that $\mathrm{pO}_{2}$ assessment is performed based on measurements of the linewidth of the LiNc$\mathrm{BuO}$ signal before injection of the NR probe. The decay of the NR signal provides the value of tissue reducing capacity as illustrated in Figure 4.

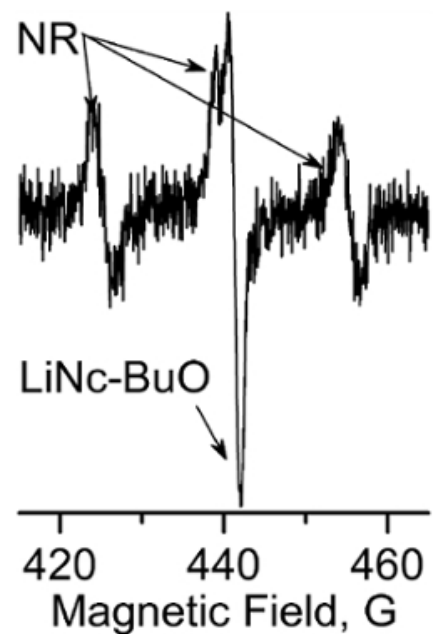

Figure 6. Multifunctional TME assessment combining LiNc-BuO and NR probes. EPR spectrum measured in vivo in breast tumor tissue of female C57BI/6 mouse immediately after i.t. injection of the NR probe. The observed triplet spectrum of the NR is superimposed with a single EPR line of LiNc-BuO probes embedded within tumor. The $\mathrm{pH}$ value calculated from the splitting between low- and high-field components is 6.88. The decay of the NR signal provides the value of tissue reducing capacity. $\mathrm{pO}_{2}$ assessment is performed based on measurements of the linewidth of the LiNc-BuO before injection of the NR probe. Please click here to view a larger version of this figure.

\section{In Vivo Assessment of Intracellular GSH:}

The reaction of thiol-disulfide exchange between the RSSR probe and GSH splits the disulfide bond of the probe resulting in the formation of two monoradicals ${ }^{22}$ and cancelation of intramolecular spin exchange between the monoradical fragments. Figure 7A illustrates the effect of the reaction of the RSSR probe with GSH on the EPR spectra resulting in the disappearance of the "biradical" spectral components and corresponding increase of the intensity of the monoradical components. The observed rate constant of the reaction between GSH and RSSR is: $\mathrm{k}_{\mathrm{obs}}=2.8 \pm 0.2 \mathrm{M}^{-1} \mathrm{~s}^{-1}\left(\mathrm{~T}=34^{\circ} \mathrm{C}, \mathrm{pH} \mathrm{7.2}\right)^{11}$. Figure 7B exemplifies the kinetics of the monoradical spectral peak intensity change measured in mammary tumor $(\bullet)$ and normal mammary gland (o) using L-band EPR. The solid lines are the fits of the initial part of the kinetics by the monoexponent using $\mathrm{k}_{\mathrm{obs}}=2.8 \mathrm{M}^{-1} \mathrm{~s}^{-1}$ and yielding $[\mathrm{GSH}]=10.7 \mathrm{mM}$ and $3.3 \mathrm{mM}$ for the tumor and normal mammary gland, respectively. 


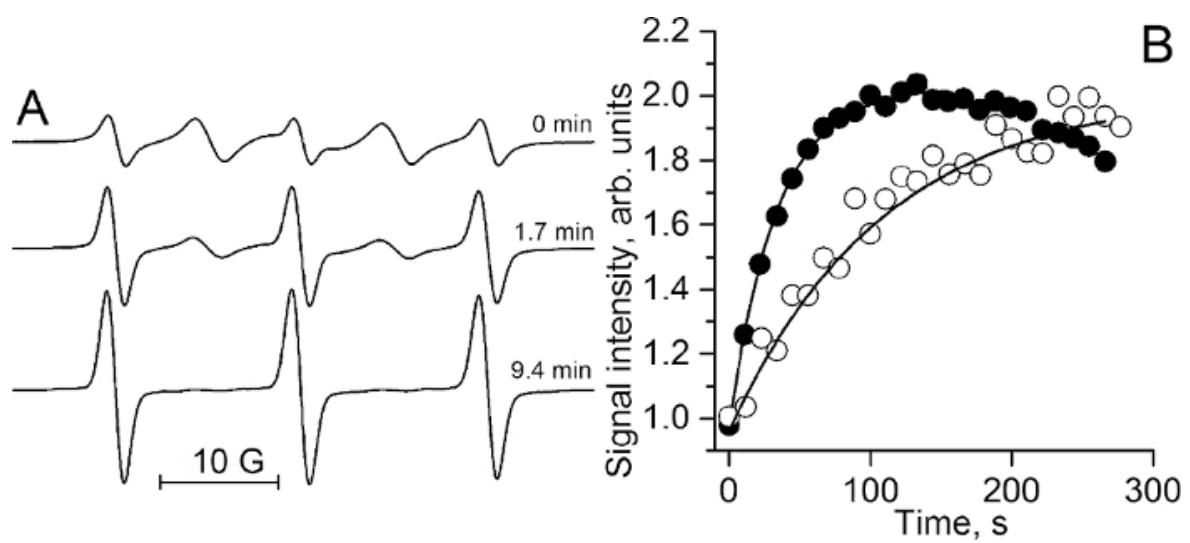

Figure 7. In vivo EPR assessment of intracellular tissue glutathione concentrations. (A) The X-band EPR spectra of $100 \mu \mathrm{M}$ RSSR measured at various time points after incubation with $2.5 \mathrm{mM} \mathrm{GSH}$ in $0.1 \mathrm{M} \mathrm{Na}$-phosphate buffer, $\mathrm{pH} 7.2$, and $1 \mathrm{mM} \mathrm{DTPA}$ at $34^{\circ} \mathrm{C}$. The kinetics analysis provides the observed rate constant value of the reaction between $\mathrm{GSH}$ and RSSR, $\mathrm{k}_{\mathrm{obs}}\left(\mathrm{pH} 7.2,34^{\circ} \mathrm{C}\right)=(2.8 \pm 0.2) \mathrm{M}^{-1} \mathrm{~s}^{-1}$. $(\mathbf{B}) \mathrm{The}$ kinetics of the monoradical spectral peak intensity change measured by L-band EPR in mammary tumor $(\bullet)$ and normal mammary gland (o) of FVB/N mice immediately after i.t. injection of RSSR probe (see step 3.3.2). The solid lines are the fits of the initial part of the kinetics by the monoexponent, supposing $\mathrm{k}_{\mathrm{obs}}\left(\mathrm{pH} 7.2,34{ }^{\circ} \mathrm{C}\right)=2.8 \mathrm{M}^{-1} \mathrm{~s}^{-1}$ and yielding $[\mathrm{GSH}]=10.7 \mathrm{mM}$ and $3.3 \mathrm{mM}$ for the tumor and normal mammary gland, respectively. Reproduced from reference ${ }^{11}$ with permission of John Wiley \& Sons, Inc. Please click here to view a larger version of this figure.

\section{Multifunctional Assessment of Tissue Extracellular $\mathrm{pH}, \mathrm{pO}_{2}$, and $\mathrm{Pi}$ Using the Multifunctional HOPE Probe:}

Figure 8 illustrates the sensitivity of the spectral parameters of the HOPE probe obtained using calibration procedures described under section 1.4 .

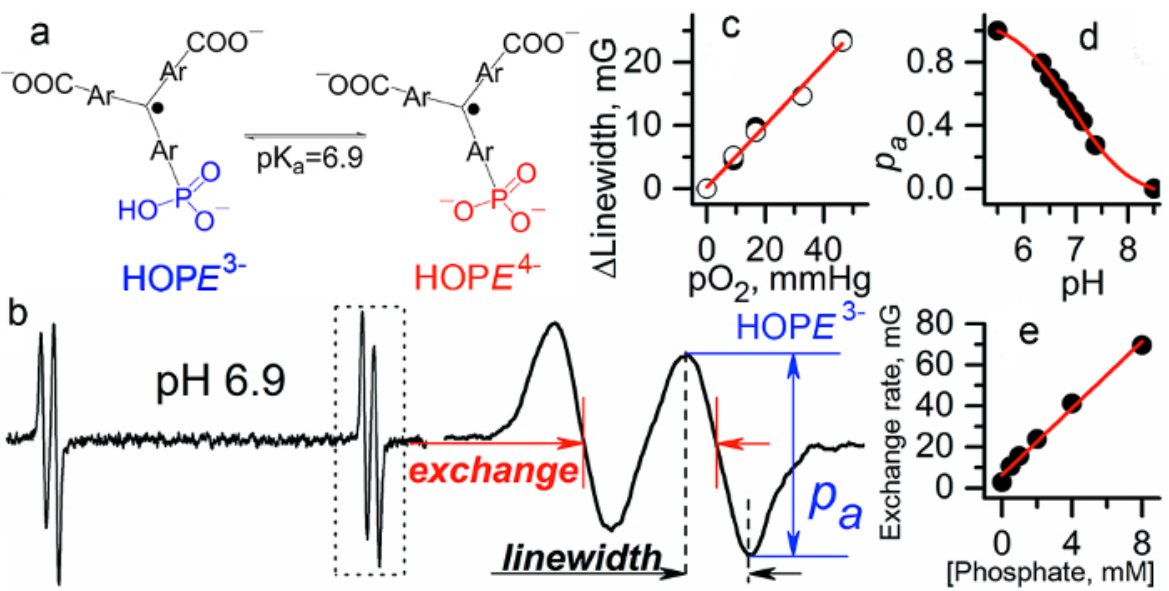

Figure 8. Multifunctional assessment of the chemical microenvironment using HOPE probe. (a) The scheme of pH-dependent equilibrium between two ionization states of the probe. (b) L-band EPR spectrum of HOPE. (c) The EPR linewidth of the HOPE is a $p \mathrm{O}_{2}$ marker (accuracy, $\approx 1 \mathrm{mmHg} ; \mathrm{O}_{2}$ range, $1-100 \mathrm{mmHg}$ ). (d) The fraction of protonated HOPE is a pH marker in the range from 6 to 8.0 (accuracy, \pm 0.05 ). (e) Dependence of proton exchange rate (expressed in $\mathrm{mG}$ ) of the HOPE with inorganic phosphate (Pi) concentration extracted by spectra simulation (accuracy, $\pm 0.1 \mathrm{mM}$, range, $0.1-20 \mathrm{mM}$ ) ${ }^{12,18}$. Reproduced from reference ${ }^{8}$ with permission of Nature Publishing Group. Please click here to view a larger version of this figure.

Figure 9 illustrates multifunctional measurements performed in FVB/N wild type mammary glands and in the TME of MMTV-PyMT transgenic mice, which spontaneously develop breast cancer and emulate human tumor staging ${ }^{20}$. The mean values of $p \mathrm{O}_{2}(50 \pm 3 \mathrm{mmHg}$ in TME vs. $58 \pm$ $3 \mathrm{mmHg}$ in normal tissue) and $\mathrm{pH}_{\mathrm{e}}(6.99 \pm 0.03$ in TME vs. $7.1 \pm 0.03$ in normal tissue) support an appearance of hypoxic and acidic regions in the tumor. The most dramatic changes were observed in the concentration of interstitial Pi $(1.8 \pm 0.2 \mathrm{mM}$ in TME vs. $0.84 \pm 0.07 \mathrm{mM}$ in normal tissue) indicating a potential role of interstitial $\mathrm{Pi}$ concentration as a TME marker of tumor progression. The individual measurements show significant variations around the mean values. An important advantage of a multifunctional probe is that all parameters are measured using a single probe, therefore allowing for correlation analyses independent of probe distribution and time of the measurements as illustrated in Figure $9 \mathrm{~b}$-e. The observed positive correlation between $\mathrm{pO}_{2}$ and $\mathrm{pH}_{\mathrm{e}}$ in normal mammary gland versus the absence of correlation in tumors supports tumor reliance on glycolysis independent of oxygen concentration; in our opinion this is an exemplified in vivo demonstration of the Warburg effect. In turn, the observed negative correlation between interstitial $[\mathrm{Pi}]$ and $p \mathrm{O}_{2}$ both in normal and tumor tissues is in agreement with the association of high [Pi] (and low ATP/Pi ratio) with changes in bioenergetics status upon lower oxygen supply. 

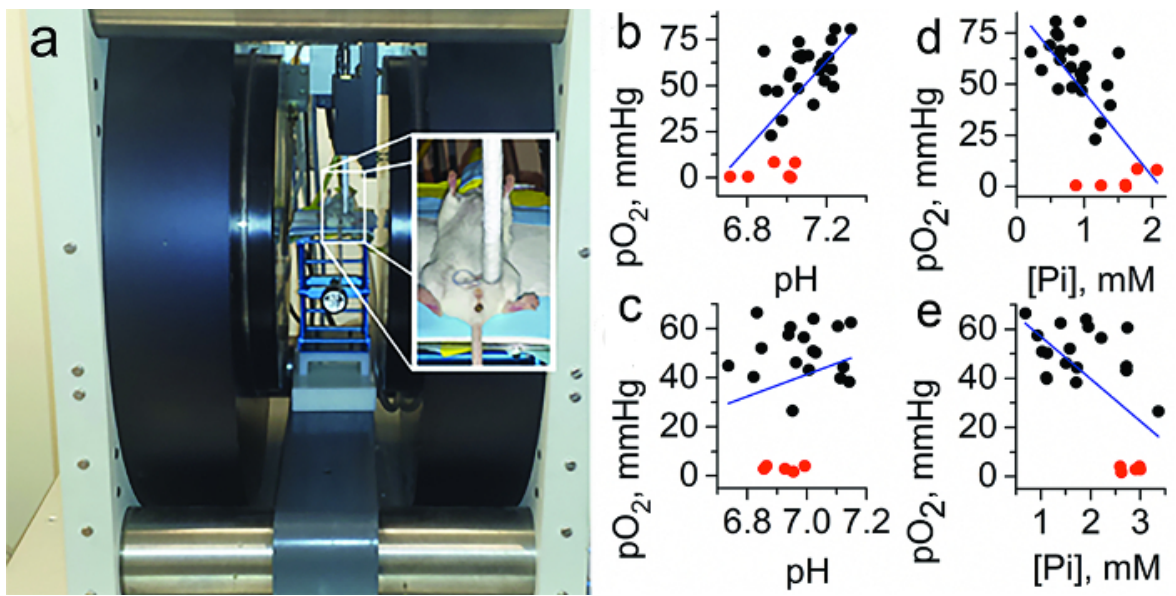

Figure 9. In vivo tissue $\mathrm{pO}_{2}, \mathrm{pH}_{\mathrm{e}}$, and $\mathrm{Pi}$ assessment using the HOPE probe and EPR. (a) Photograph of the set-up for in vivo L-band EPR measurements shows the anesthetized mouse between the magnets of the EPR spectrometer, with the insert on the right showing placement and positioning of the loop resonator on top of the measured tissue. Note the interstitial extracellular localization of the HOPE probe: it does not penetrate into the cells due to bulky charged structures and the HOPE signal from the blood is not detected by EPR due to signal broadening by HOPE complexation with plasma albumin ${ }^{24}$. (b-e) Correlation between interstitial $\mathrm{pO}_{2}, \mathrm{pH}_{\mathrm{e}}$, and $\mathrm{Pi}$ values measured in normal mammary glands of FVB/N wild type mice and in the TME of breast cancer in MMTV-PyMT transgenic mice $(n=23)$. To extend the range of oxygen variations, anoxic conditions in interstitial space were established by i.t. injection of the oxygen-consuming enzymatic system of glucose/glucose oxidase (red symbols). Blue lines represent a linear fit for the total data sets. (b) A positive correlation between $p \mathrm{O}_{2}$ and $\mathrm{pH}_{\mathrm{e}}$ in normal tissue ( $\mathrm{r}=0.5, p$ $=0.014$ for black symbols; $r=0.64, p=1.8 \times 10^{-4}$ for total data set) vs. (c) no significant correlation between $p \mathrm{O}_{2}$ and $\mathrm{pH}_{\mathrm{e}}$ in TME $(r=0.01, p=$ 0.97 for black symbols; $r=0.23, p=0.3$ for total data set) were found. (d) A negative correlation between $p \mathrm{O}_{2}$ and $\mathrm{Pi}$ both in normal tissue $(r=$ $-0.51, p=0.013$ for black symbols; $r=-0.7, p=2.3 \times 10^{-5}$ for total data set) and (e) in TME (b, bottom: $r=-0.4, p=0.079$ for black symbols; $r$ $=-0.62, p=0.001$ for total data set) were found. Adapted from reference ${ }^{8}$ with permission with of Nature Publishing Group. Please click here to view a larger version of this figure.

\section{Discussion}

The presented methods allow for noninvasive in vivo assessment of the critical parameters of the chemical $\mathrm{TME}, \mathrm{namely} p \mathrm{O}_{2}, \mathrm{pH}, \mathrm{redox}$ status, and concentrations of interstitial $\mathrm{Pi}$ and intracellular GSH. Magnetic resonance techniques, such as MRI and low-field EPR, are the methods of choice for noninvasive in vivo profiling of these TME parameters. MRI visualizes anatomical structures but lacks functional sensitivity. In contrast to MRI, EPR techniques provide functional sensitivity to the local parameters of the microenvironment when used in combination with functional spin probes. To our knowledge, there are no other methods available to concurrently assess in vivo physiologically important chemical TME parameters in living subjects, such as $\mathrm{pO}_{2}, \mathrm{pH}_{\mathrm{e}}, \mathrm{Pi}$, redox, and $\mathrm{GSH}$.

The described protocols are based on using low-field L-band EPR and specially designed paramagnetic probes. A set of four probes presented in Figure 1 can be considered an effective in vivo TME assessment assay. Availability of the probes is an important prerequisite for the described in vivo EPR measurements. The synthesis of the probes according to the published procedures ${ }^{11,12,13,15}$ requires expertise in synthetic organic chemistry and may become a critical step for the method implementation.

Application of the particulate probe enables repeated measurements of tissue $\mathrm{pO}_{2}$ for up to weeks after implantation ${ }^{14,21}$. Soluble probes demonstrate sensitivity to an extended number of the parameters beyond oxygen concentration ${ }^{25}$ and provide an opportunity for spatial-resolved measurements ${ }^{26}$. In particular, an application of the multifunctional HOPE probe provides unsurpassed opportunity for in vivo concurrent measurements of $\mathrm{pH}, \mathrm{pO}_{2}$, and $\mathrm{Pi}$ in extracellular space. The measurements of the three parameters using a single probe allows for their correlation analyses independent of probe distribution and time of the measurements ${ }^{8}$.

The probes cannot be used simultaneously, except for the implanted LiNc-BuO particulate probe, which can be used in combination with any of the soluble probes as demonstrated in Figure 6. Therefore, the experimental design should be based on separate measurements of individual injections of specific functional soluble probes. The hydrophilic extracellular $\mathrm{pH}$ and redox NR probe can be delivered both via i.t. injection ${ }^{11,14,26}$ and systemic delivery ${ }^{27}$, while two other soluble probes, RSSR and HOPE, allow for i.t. delivery only ${ }^{8,11,12,16}$. Note that the future structural modifications of RSSR and HOPE probes may overcome the latter limitation of probe delivery by the development of more hydrophilic and less toxic probe analogs for systemic delivery ${ }^{25}$.

Note that spectroscopic EPR modality provides the average values of the parameters measured in the TME, which is often characterized by its high heterogeneity. This partially masks the potential differences between the parameters or decreases significance in correlation analysis. The use of the described probes in imaging modalities allows for obtaining spatially-resolved functional information ${ }^{26}$. We believe that the future of multi-functional EPR imaging relies on the further development of relatively new methodologies such as rapid scan EPR imaging and Overhauser-enhanced MRI (OMRI, also termed proton-electron double-resonance imaging, PEDRI). The new directions in the development of functional EPR probes and advanced imaging techniques have been recently discussed in the corresponding feature article ${ }^{25}$. 


\section{Disclosures}

The authors have nothing to disclose.

\section{Acknowledgements}

This work was partially supported by NIH grants CA194013, CA192064 and U54GM104942. The WVCTSI is acknowledged for start-up to VVK, $A B$, and TDE. The authors thank Dr. M. Gencheva and K. Steinberger for the assistance with the illustrative experiments. The content is solely the responsibility of the authors and does not necessarily represent the official views of the NIH.

\section{References}

1. Siemann, D. W. Tumor Microenvironment. John Wiley \& Sons, Ltd., Chichester, UK; Hoboken, NJ, USA (2011).

2. Tatum, J. L. et al. Hypoxia: importance in tumor biology, noninvasive measurement by imaging, and value of its measurement in the management of cancer therapy. Int J Radiat Biol. 82 (10), 699-757 (2006).

3. Brahimi-Horn, M. C., Chiche, J., \& Pouyssegur, J. Hypoxia signalling controls metabolic demand. Curr Opin Cell Biol. 19 (2), 223-229 (2007).

4. Haulica, A., \& Ababei, L. Comparative study of glycolytic activity in the erythrocytes of animals with chronic experimental hypoxia and with tumours. Neoplasma. 21 (1), 29-35 (1974).

5. Matsumoto, K. et al. High-resolution mapping of tumor redox status by magnetic resonance imaging using nitroxides as redox-sensitive contrast agents. Clin Cancer Res. 12 (8), 2455-2462 (2006).

6. Estrela, J. M., Ortega, A., \& Obrador, E. Glutathione in cancer biology and therapy. Crit Rev Clin Lab Sci. 43 (2), 143-181 (2006).

7. Voegtlin, C., \& Thompson, J. W. Glutathione content of tumor animals. J. Biol. Chem. 70 801-806 (1926).

8. Bobko, A. A. et al. Interstitial Inorganic Phosphate as a Tumor Microenvironment Marker for Tumor Progression. Sci Rep. 741233 (2017).

9. Gillies, R. J., Raghunand, N., Garcia-Martin, M. L., \& Gatenby, R. A. pH imaging. A review of pH measurement methods and applications in cancers. IEEE Eng Med Biol Mag. 23 (5), 57-64 (2004).

10. Gade, T. P. et al. Imaging intratumoral convection: pressure-dependent enhancement in chemotherapeutic delivery to solid tumors. Clin Cancer Res. 15 (1), 247-255 (2009).

11. Bobko, A. A. et al. In vivo monitoring of $\mathrm{pH}$, redox status, and glutathione using L-band EPR for assessment of therapeutic effectiveness in solid tumors. Magn Reson Med. 67 1827-1836 (2012)

12. Dhimitruka, I., Bobko, A. A., Eubank, T. D., Komarov, D. A., \& Khramtsov, V. V. Phosphonated Trityl Probe for Concurrent In Vivo Tissue Oxygen and pH Monitoring Using EPR-based Techniques. JACS. 135 5904-5910 (2013).

13. Pandian, R. P., Parinandi, N. L., llangovan, G., Zweier, J. L., \& Kuppusamy, P. Novel particulate spin probe for targeted determination of oxygen in cells and tissues. Free Radic Biol Med. 35 (9), 1138-1148 (2003).

14. Bobko, A. A., Evans, J., Denko, N. C., \& Khramtsov, V. V. Concurrent Longitudinal EPR Monitoring of Tissue Oxygenation, Acidosis, and Reducing Capacity in Mouse Xenograft Tumor Models. Cell Biochem Biophys. 75 247-253 (2017).

15. Khramtsov, V. V., Yelinova, V. I., Glazachev Yu, I., Reznikov, V. A., \& Zimmer, G. Quantitative determination and reversible modification of thiols using imidazolidine biradical disulfide label. J Biochem Biophys Methods. 35 (2), 115-128 (1997).

16. Roshchupkina, G. I. et al. In vivo EPR measurement of glutathione in tumor-bearing mice using improved disulfide biradical probe. Free Rad. Biol. Med. 45 312-320 (2008).

17. Khramtsov, V. V., \& Zweier, J. L. in Stable Radicals: Fundamentals and Applied Aspects of Odd-Electron Compounds .(ed Robin Hicks), pp. 537-566, John Wiley \& Sons, Ltd., (2010).

18. Bobko, A. A., Dhimitruka, I., Zweier, J. L., \& Khramtsov, V. V. Fourier Transform EPR of Trityl Radicals for Multifunctional Assessment of Chemical Microenvironment. Angew. Chem. Int. Edit. 53 2735-2738 (2014).

19. Martin, M. L., Martin, G. J., \& Delpuech, J.-J. Practical NMR spectroscopy. Heyden, (1980).

20. Lin, E. Y. et al. Progression to malignancy in the polyoma middle T oncoprotein mouse breast cancer model provides a reliable model for human diseases. Am J Pathol. 163 (5), 2113-2126 (2003).

21. Eubank, T. D. et al. Granulocyte macrophage colony-stimulating factor inhibits breast cancer growth and metastasis by invoking an antiangiogenic program in tumor-educated macrophages. Cancer Res. 69 (5), 2133-2140 (2009).

22. Khramtsov, V. V. et al. Quantitative determination of SH groups in low- and high-molecular-weight compounds by an electron spin resonance method. Anal Biochem. 182 (1), 58-63 (1989).

23. Komarov, D. A. et al. Electron paramagnetic resonance monitoring of ischemia-induced myocardial oxygen depletion and acidosis in isolated rat hearts using soluble paramagnetic probes. Magnetic Resonance in Medicine. 68 (2), 649-655 (2012).

24. Song, Y. G., Liu, Y. P., Liu, W. B., Villamena, F. A., \& Zweier, J. L. Characterization of the binding of the Finland trityl radical with bovine serum albumin. Rsc Advances. 4 (88), 47649-47656 (2014).

25. Khramtsov, V. V., Bobko, A. A., Tseytlin, M., \& Driesschaert, B. Exchange Phenomena in the Electron Paramagnetic Resonance Spectra of the Nitroxyl and Trityl Radicals: Multifunctional Spectroscopy and Imaging of Local Chemical Microenvironment. Analyt. Chem. 89 (9), 4758-4771 (2017).

26. Samouilov, A. et al. In Vivo Proton-Electron Double-Resonance Imaging of Extracellular Tumor pH Using an Advanced Nitroxide Probe. Analyt. Chem. 86 (2), 1045-1052 (2014).

27. Goodwin, J. et al. In vivo tumour extracellular $\mathrm{pH}$ monitoring using electron paramagnetic resonance: the effect of $\mathrm{X}$-ray irradiation. NMR Biomed. 27 ( 4), 453-458 (2014) 